\title{
International Co-movements and Business Cycles Synchronization Across Advanced Economies: A SPBVAR Evidence
}

\author{
Antonio Pacifico \\ Correspondence: Antonio Pacifico, Department of Political Sciences, LUISS Guido Carli University and CEFOP-LUISS, \\ Rome, Italy, 00197. E-mail: antonio.pacifico86@gmail.com or apacifico@luiss.it
}

Received: June 3, 2019 Accepted: June 30, 2019 Online Published: July 2, 2019

doi:10.5539/ijsp.v8n4p68 URL: https://doi.org/10.5539/ijsp.v8n4p68

\begin{abstract}
This paper provides new empirical insights in order to give a relevant contribution to the more recent literature on international transmission of shocks and on business cycles synchronization across developed economies, with a particular emphasis in the most recent recession and post-crisis consolidation. Interdependence, commonality and heterogeneity in macroeconomic-financial linkages are also identified in order to depict the perplexed nature of modern economies. A time-varying Structural Panel Bayesian Vector Autoregression (SPBVAR) model is developed to deal with model misspecification and unobserved heterogeneity problems when studying multicountry dynamic panels. The results argue for significant synchronization behind a relevant consolidation without delay. Additionally, consolidation is needed to underpin confidence in fiscal solvency at the country level and prevent adverse international externalities. My evidence calls for more integrated macroprudential and financial stability policies. It also shows that, when formulating policies or forecasting, additional transmission channels and economic-institutional issues through which fiscal contractions influence the dynamics of the GDP growth need to be accounted for in muticountry setups.
\end{abstract}

Keywords: panel VAR, bayesian inference, macro-financial linkages, structural spillovers, MCMC implementations

\section{Introduction}

Fiscal policy has critical implications for economic growth both in the short and the long run. At the same time, strong growth greatly facilitates fiscal adjustment, both in the short and over the long run. Policymakers need to be aware of this interaction as sizeable fiscal adjustment is needed in most advanced countries over the coming years in order to bring down the debt to GDP ratio, which has reached a historical peak seen only once in the last 20 years. Implementation of fiscal consolidation by advanced economies in coming years needs to take into account potential interactions between additional transmission channels and economic-institutional factors when studying macroeconomic-financial linkages in multicountry data. In this context, the issue of international business cycle linkages, or more generally, of possible co-movements in economic activity across countries and regions has recently resurfaced to the attention of analysts, policymakers and academic scholars. The simultaneous slowdown experienced to different degrees by all the G7 and other advanced economies, starting before and during the recent recession, underlines that the developments even in relatively large economies cannot always be analysed in isolation. For policymakers, the ability to gauge the nature and the magnitude of cross-country co-movements in economic activity may be crucial in order to assess the developments in their own domestic economy.

Several studies have focused on the existence of commonalities in economic activity across countries using a variety of methods (see, e.g., Baxter \& Stockman (1989), Backus \& Kehoe (1992), and Gregory et al. (1997)). Here, economicinstitutional issues can be accounted for by the presence of interdependencies in either real or financial dimension, which spill country and variable specific shocks. Nevertheless, in an international context, the generation and transmission of business cycles have only been partially analyzed with the tools of modern economies (see, e.g., Cantor \& Mark (1987) and Canova \& Della (1993)). Knowledge of what generates and transmits cycles across countries is important for policy implications and suggestions for decision makers. For istance, there are many additional channels through which macroeconomic and financial linkages can vary across countries and over time, and the final effect on the economy depends not only on agents' behavior but also on the institutional framework they operate in. Thus, when formulating policies or forecasting, additional issues need to be considered, such as the reasons underlying the different reactions among countries, the additional transmission channels that allow shocks to spill over, and the economic and institutional implications of driving shock transmission. However, in evaluating cross-country international business cycles and changes in cyclical comovements, heterogeneous dynamics due to an unexpected shock combined with economic-institutional interdependencies are difficult to be estimated in multicountry setups. 
From a methodological point of view, I build on Pacifico (2019), who develops a time-varying Structural Panel Bayesian Vector Autoregression (SPBVAR) model to deal with model misspecification and unobserved heterogeneity problems when jointly modelling and quantifying multicountry data using the information contained in a large set of endogenous and economic-institutional variables. Markov Chain Monte Carlo (MCMC) implementations (see, e.g., Chib (1995, 1996), Chib \& Albert (1993), Chib \& Jeliazkov (2001), Pesaran \& Shinb (1998), and Carter \& Kohn (1994)) and hierarchical priors (see, e.g., Koop (1996), Canova \& Ciccarelli (2004, 2009), Ciccarelli et al. (2018), and Pacifico (2019)) are defined to calculate posterior distributions of Conditional Generalized Impulse Response Functions (CGIRFs) and Conditional Forecasts (CF) reacting to unexpected perturbations in the innovations of factors in the system. Bayesian methods are used to reduce the dimensionality of the model and jointly evaluate issues of endogeneity and business cycles synchronization when studying macroeconomic-financial linkages in muticountry data. In this paper, I further build on Ciccarelli et al. (2018) and Pacifico (2019), by using a Structural Normal Linear Regression (SNLR) model in order to work with smaller systems in which the regressors are endogenous, directly measured, and time-varying linear combinations of the right-hand variables of the time-varying SPBVAR. I also account for structural Bilateral Net Spillover Effects (BNSEs) and Systemic Contributions (SCs) in order to quantify structural spillovers and thus to evaluate interdependencies, co-movements, and heterogeneities among different countries and sectors (see, e.g., Pacifico (2019)).

Empirically, in the more recent literature on international business cycles, there is no consensus on the heterogeneous dynamics of international transmission of shocks and on the degree of the synchronization of business cycles among different sectors and countries. For example, Canova \& Marrinan (1998) investigate the generation and the transmission of business cycles using a multi-country general equilibrium model with production and consumption interdependencies. They address the question whether international business cycles originate from common shocks or from a common propagation mechanism. They find evidence on significant cross-country heterogeneities in helping to induce some of the asymmetries in the data and to more closely replicate the impulse response function following German output shocks. However, the model focuses on the only real economy and thus is not able to include heterogeneous dynamics across developed economies and investigate asymmetric transmission of shocks. Ciccarelli et al. (2018) investigate heterogeneity and spillovers in macro-financial linkages among developed economies, focusing on the most recent recession. They develop a time-varying panel Bayesian VAR model including real and financial variables and identify a statistically significant common component. Nevertheless, their empirical model is non-structural and constrained because of time-invariant or exogenous factors in the system, so it is unable to identify structural and institutional differences among countries, different reactions to a common unexpected shock, and the causality among real and financial variables. Doyle \& Faust (2003) investigate changes in the variability of and comovement among growth rates of G7 countries (often without Japan). Besides descriptive methods, they employ a Vector Autoregression (VAR) model with one lag and a constant where all the parameters are allowed to break at a fixed number of dates. They test whether the parameters they are interested in correlation coefficients change over time. They find no clear evidence that correlation has increased with the rising economic integration of the last years and decades because of inability of the model in investigating for dynamic interdependencies among sectors and countries. Inklaar \& De Haan (2001) try to reproduce findings by Artis \& Zhang $(1997,1999)$ who stated that after installment of the European Monetary System the business cycle synchronization of most member countries shifted from the United States to Germany. However, they find no evidence because of different cyclical comovements across countries.

My approach and empirical application aim to give a valid contribution to such studies by focusing on a pool of real and financial variables and a set of not directly observed factors for advanced economies, with particular emphasis on the recent recession and post-crisis consolidation. Of a total of 10 countries, 7 belong to the European Union and of those, 5 are euro area members. The empirical analysis has two specific objectives. The first is to isolate and to measure how an unexpected shock affects the degree of output growth co-movements amongst advanced economies and thus to assess the relative importance of potential cross-country interconnections and interdependencies among macroeconomicfinancial variables, with a particular emphasis on the most recent recession and fiscal consolidation. In addition, the paper investigates the degree of international business cycles synchronization and the changes in cyclical comovements for a pool of advanced economies, by accounting for additional transmission channels and economic-institutional issues in order to avoid model misspecification and unobserved heterogeneity problems when dealing with dynamic multicountry data. The analysis is robust and consistent with the more recent business cycle studies, which recognize the importance of (1) accounting for both group-specific and global factors when evaluating cross-country spillovers, (2) separating common shocks from the propagation of country- and variable-specific shocks when studying economic-financial linkages (see, e.g., Dees et al. (2007), Forni et al. (2000), Ciccarelli et al. (2018), Canova \& Marrinan (1998); Canova et al. (2012), and Beetsma \& Giuliadori (2011)), and (3) accounting for additional transmission channels and economic-institutional linkages when using multicountry dynamic data (see, e.g., Pacifico (2019)).

From a modelling perspective, I confirm that growth shocks spill over in a heterogeneous way among countries, although a 
significant common component holds, mainly during the crisis period and even more so during post-crisis consolidations. Over time, commonalities are stronger in the financial dimension, where shock transmission is more intense. Moreover, the analysis suggests that area-specific common factors play an important role, separating the sample into a North American (US, Canada) and a continental European (France, Germany, Italy) area, with the Ireland and Japan being somewhat separate from these areas. I find that developments in the North American factor have a strong lagged impact on the continental European factor, while the reverse is not true. Furthermore, the strength of the cross-area spillovers from America to Europe appears to have become stronger over the sample period, suggesting that international linkages have increased in the process of globalization. Finally, international business cycles seem to have become more synchronized over time across advanced economies and even more among euro-area countries, especially in the last decade, behind coordinated fiscal actions.

From a policy perspective, some considerations are in order. First, cross-country heterogeneity and interdependency in the financial dimension tend to be driven by stringent international institutional constraints and pressures. Thus, without dealing with unobserved heterogeneity, the synchronization seems to be likely decreasing over time due to different countries' reactions given an unexpected shock. Second, the consolidations tend to occur simultaneously over time behind more coordinated fiscal actions across euro-area countries, but it is not the same for other advanced economies. Finally, accounting for additional transmission channels and economic-institutional issues, the analysis shows that the degree of synchronization is relevant across advanced economies and even more across euro-area countries. More precisely, it is highlighted in the real economy where commonality and homogeneity matter more because of relevant international trade exposures. These results cast a new perspective for theoretical models of the international business cycles, as well as for policy making.

The remainder of this paper is organized as follows. Section 2 introduces the econometric model and the estimation procedure. Section 3 presents the data and the empirical analysis. Section 4 evaluates the transmission of international shocks among countries and sectors. Section 5 outlines the evolution of structural spillover effects during the recent recession and post-crisis consolidation highlighting policy implications for decision makers. The final section contains some concluding remarks.

\section{Empirical Model and Specifications}

I use the time-varying SPBVAR model developed by Pacifico (2019), including lagged endogenous variables and a set of not directly observed variables. The model has the form:

$$
Y_{i t}^{m}=A_{i, 0}+A_{i t, j}^{m}(L) Y_{i, t-1}^{m}+B_{i t, j}^{q}(L) W_{i, t-1}^{q}+C_{i t, j}^{\xi}(L) Z_{i, t-1}^{\xi}+\varepsilon_{i t}
$$

where the subscripts $i, j=1,2, \ldots, N$ are country indices, $t=1,2, \ldots, T$ denotes time, $L$ stands for the lag operator, $A_{i, 0}$ is an $N M \cdot 1$ vector of intercepts for each $i, A_{i t, j}$ is an $N M \cdot N M$ matrix of coefficients for each pair of countries $(i, j)$ for a given $m, Y_{i, t-1}$ is an $N M \cdot 1$ vector of lagged variables of interest for each $i$ for a given $m, B_{i t, j}$ is an $N Q \cdot N Q$ matrix of coefficients for each pair of countries $(i, j)$ for a given $q, W_{i, t-1}$ is an $N Q \cdot 1$ vector including a set of lagged directly observed variables for each $i$ for a given $q, C_{i t, j}$ is an $N \Xi \cdot N \Xi$ matrix of coefficients for each pair of countries $(i, j)$ for a given $\xi, Z_{i, t-1}$ is an $N \Xi \cdot 1$ vector including a set of lagged not directly observed variables for each $i$ for a given $\xi$, and $\varepsilon_{i t} \sim$ i.i.d. $N(0, \Sigma)$ is an $N M \cdot 1$ vector of disturbance terms. According to the Schwartz-Bayesian Information Criterion, the model is estimated with only one lag of all $m=1, \ldots, M$ endogenous variables, $q=1, \ldots, Q$ (directly) observed variables, and $\xi=1, \ldots, \Xi$ hidden variables. Here, all variables in the system are endogenous and time-varying.

The model 1 displays three important features which makes it ideal for studying the evolution of cyclical fluctuations and the degree of international business cycles. First, dynamic relationships are allowed to be unit-specific, and all coefficients vary over time. Second, whenever the matrices $A_{i t, j}(L), B_{i t}(L)$, and $C_{i t}(L)$ differ for some $L$, cross-unit lagged interdependencies matter, and then dynamic feedback and interactions among countries and among variables are possible (Note 1). Third, the structural framework of the model is able to connect the empirical results to the existing literature and to contemporaneous developments. For example, I can assess ( $i$ ) how the dimension and intensification of spillovers over time affect commonality, interdependence, and heterogeneity among countries and variables; (ii) interdependencies in international business cycles among sectors and countries; (iii) how different transmission channels essentially affect the spread of spillovers in macroeconomic-financial linkages when given an unexpected shock; and (iv) the importance of economic and institutional implications in driving shock transmission.

The model 1 can be re-written in a simultaneous-equation form:

$$
Y_{t}=\left(I_{N M} \otimes X_{t}\right) \gamma_{t}+E_{t}
$$


where $Y_{t}=\left(Y_{1 t}^{m^{\prime}}, \ldots, Y_{N t}^{m^{\prime}}\right)^{\prime}$ is an $N M \cdot 1$ vector containing the observable variables of interest for each $i$ for a given $m$, $E_{t}=\left(\varepsilon_{1 t}^{\prime}, \ldots, \varepsilon_{N t}^{\prime}\right)^{\prime}$ is an $N M \cdot 1$ vector containing the random disturbances of the model, $X_{t}=\left(I, Y_{i, t-1}^{\prime m}, W_{i, t-1}^{\prime q}, Z_{i, t-1}^{\prime}\right)^{\prime}$ is an $1 \cdot k$ vector containing all lagged variables in the system for each $i, \gamma_{i t, j}^{k}=v e c\left(g_{i t, j}^{k}\right)$ is an $N M k \cdot 1$ vector containing all columns, stacked into a vector of the matrices $A_{t}(L), B_{t}(L)$, and $C_{t}(L)$ for each pair of countries $(i, j)$ for a given $k$, with $k=N[M+Q+\Xi] l$ denoting the number of all matrix coefficients in each equation of the SPBVAR model for each pair of countries $(i, j), g_{i t, j}^{k}=\left(A_{i, 0}^{\prime}, A_{i t, j}^{1^{\prime}}, A_{i t, j}^{2^{\prime}}, \ldots, A_{i t, j}^{M^{\prime}}, B_{i t, j}^{1^{\prime}}, B_{i t, j}^{2^{\prime}}, \ldots, B_{i t, j}^{Q^{\prime}}, C_{i t, j}^{1^{\prime}}, C_{i t, j}^{2^{\prime}}, \ldots, C_{i t, j}^{\Xi^{\prime}}\right)^{\prime}$, and $\gamma_{t}=\left(\gamma_{1 t}^{\prime}, \gamma_{2 t}^{\prime}, \ldots, \gamma_{N t}^{\prime}\right)^{\prime}$ denoting the time-varying coefficient vectors, stacked for $i$, for each country-variable pair. In model 2 there is no subscript $i$ since all lagged variables in the system are stacked in $X_{t}$.

To cope with the curse of dimensionality, I adapt the framework in Pacifico (2019) and assume $\gamma_{t}$ has the following factor structure:

$$
\gamma_{t}=\sum_{f=1}^{F} G_{f} \cdot \beta_{f t}+u_{t} \quad \text { with } \quad u_{t} \sim N\left(0, \Sigma_{u}\right)
$$

where $F \ll N M k$ and $\operatorname{dim}\left(\beta_{f t}\right) \ll \operatorname{dim}\left(\gamma_{t}\right)$ by construction; $G_{f}=\left[G_{1}, G_{2}, \ldots, G_{F}\right]$ are $N M k \cdot \varkappa^{f}$ matrices obtained by multiplying the matrix coefficients $\left(g_{i t, j}^{k}\right)$ stacked in the vector $\gamma_{t}$ by conformable matrices $D_{f}$ with elements equal to zero and one, where $\varkappa^{f}$ is a numerical index that depends on the typology of the factorization, $u_{t}$ is an $N M k \cdot 1$ vector of unmodeled variations present in $\gamma_{t}, E\left(u_{t} u_{t}^{\prime}\right)=\Sigma_{u}=\Sigma_{e} \otimes V$, where $\Sigma_{e}$ is the covariance matrix of the vector $E_{t}$, and $V=\left(\sigma^{2} I_{k}\right)$ as in Kadiyala \& Karlsson (1997). In the framework, unobserved heterogeneity and model specification are absorbed in the $\varkappa^{f} \cdot 1$ time-varying coefficient vectors $\beta_{f t}$. They are observable smooth linear functions of the lagged variables and can thus be easily estimated with a gain in efficiency (Note 2 ).

The idea is to shrink $\gamma_{t}$ to a much smaller dimensional vector $\beta_{t}$, with $\beta_{t}=\left(\beta_{1 t}^{\prime}, \beta_{2 t}^{\prime}, \ldots, \beta_{F t}^{\prime}\right)^{\prime}$, containing all regression coefficients stacked into a vector. Running equations 2 and 3 for equation 1, I assume that the coefficient vector $\gamma_{t}$ depends on ten factors. Thus,

$$
G_{f} \beta_{f t}=G_{1} \beta_{1 t}+G_{2} \beta_{2 t}+G_{3} \beta_{3 t}+G_{4} \beta_{4 t}+G_{5} \beta_{5 t}+G_{6} \beta_{6 t}+G_{7} \beta_{7 t}+G_{8} \beta_{8 t}+G_{9} \beta_{9 t}+G_{10} \beta_{10 t}+u_{t}
$$

where, stacking for $t, \beta_{f}=\left(\beta_{1}, \beta_{2}, \beta_{3}, \beta_{4}, \beta_{5}, \beta_{6}, \beta_{7}, \beta_{8}, \beta_{9}, \beta_{10}\right)^{\prime}$ contains all time-varying coefficient vectors to be estimated.

Given the factorization in equation 4, the reduced-form SPBVAR model in equation 2 can be transformed into a Structural Normal Linear Regression (SNLR) model with an error covariance matrix of an Inverse-Wishart $(I W)$ distribution. By equations 2 and 3, the SNLR model can be written as

$$
Y_{t}=\Theta_{t}\left(\sum_{f=1}^{10} G_{f} \beta_{f t}+u_{t}\right)+E_{t} \equiv \chi_{f t} \beta_{f t}+\eta_{t} \quad \text { with } \quad \Theta_{t}=\left(I_{N M} \otimes X_{t}\right)
$$

where $\Theta_{t}$ contains all lagged time-varying variables in the system by construction, $\chi_{f t} \equiv \Theta_{f t} G_{f t}$ is an $N M \cdot \varkappa^{f}$ matrix that stacks all coefficients of the system, with $\chi_{t}=\operatorname{diag}\left(\chi_{1 t}^{\prime}, \chi_{2 t}^{\prime}, \ldots, \chi_{F t}^{\prime}\right)$, and $\eta_{t} \equiv \Theta_{f t} u_{t}+E_{t} \sim N\left(0, \sigma_{t} \cdot \Sigma_{u}\right)$ has a particular heteroskedastic covariance matrix that needs to be taken into account, with $\sigma_{t}=\left(I_{N}+\sigma^{2} \Theta_{t}^{\prime} \Theta_{t}\right)$. If the factorization in equation 4 is exact (Note 3$), \eta_{t} \sim N(0, \ddot{\Sigma})$, with $\ddot{\Sigma}=\operatorname{diag}\left(\Sigma_{e}^{\prime}, \Sigma_{e}{ }^{\prime}, \ldots, \Sigma_{e}^{\prime}\right)$, depends on the only disturbances contained in $E_{t}$. Thus, it is uncorrelated with the regressors, and classical OLS can be used to estimate the vector $\beta_{t}$ and thus the vector $\gamma_{t}$. The correlation tends to decrease as $k$ increases, and consistency is ensured as $T$ grows. In equation $5, \chi_{f t}=\left(\chi_{1 t}^{\prime}, \chi_{2 t}^{\prime}, \chi_{3 t}^{\prime}, \chi_{4 t}^{\prime}, \chi_{5 t}^{\prime}, \chi_{6 t}^{\prime}, \chi_{7 t}^{\prime}, \chi_{8 t}^{\prime}, \chi_{9 t}^{\prime}, \chi_{10 t}^{\prime}\right)$ contains all stacked coefficients and their possible interactions in the SPBVAR model in equation 1 .

To complete the specification, I suppose the following state-space structure:

$$
\beta_{t}=\beta_{t-1}+v_{t} \quad \text { with } \quad v_{t} \sim N\left(0, H_{t}\right)
$$

where $\beta_{t}=\left(\beta_{1 t}, \beta_{2 t}, \ldots\right)^{\prime}, H_{t}=\operatorname{diag}\left(\bar{H}_{1 t}, \bar{H}_{2 t}, \ldots, \bar{H}_{10 t}\right)$ is a block diagonal matrix, and $\bar{H}_{f t}=\left(h_{f t} \cdot I\right)$, where $h_{f t}$ controls the tightness (stringent conditions) of the factorization $(f)$ of the time-varying coefficient parameter $\left(\beta_{t}\right)$ in order to make it estimable. The errors $E_{t}, u_{t}$, and $v_{t}$ are mutually independent. The random-walk assumption in 6 is very common in the time-varying VAR literature and has the advantage of focusing on permanent shifts and reducing the number of parameters in the estimation procedure (Note 4). 


\section{Data Description and Selected Factors}

The model is estimated for G7 economies [Canada (CA), France (FR), Germany (DE), Italy (IT), Japan (JP), the United Kingdom (UK), and the United States (US)] and for some non-G7 European countries [Ireland (IE), Spain (ES), and Sweden (SE)] using core variables of the real business cycles and a set of financial variables. In addition, two transmission channels in real and financial dimension and six not directly observed variables are evaluated in order to deal with misspecification and unobserved heterogenity problems when studying macroeconomic-financial linkages in dynamic multicountry data. The dataset contains the following collection of variables. (i) Six endogenous variables are involved to describe the real $\left(\mathrm{real}_{i t, j}\right)$ and financial $\left(\mathrm{fin}_{i t, j}\right)$ dimensions: three real variables (general government spending, gross fixed capital formation, GDP growth rate) and three financial variables (general government debt, current account balance, interest rate). (ii) Bilateral flows of trade ( $r w e i g h t s_{i t, j}$ ) and capital ( $f$ weight $s_{i t, j}$ ) are used to capture unobserved heterogeneity among countries and variables when investigating additional transmission channels that affect shock identification and spillover effects. (iii) Six (directly) observed variables are used as proxy variables to evaluate macroeconomic-institutional implications ( structures $_{i t, j}$ ) in driving the transmission of shocks among countries and variables: one indicator monitors external positions (net international investments); one indicator captures competitiveness developments and catching-up effects (nominal labor cost); three indicators reflect internal imbalances (general government consumption, private sector consumption, and change in unemployment rate); and one indicator monitores the probabilities of transitions between expansion/recession phases in business cycles and potential macroeconomic imbalances (house price indeces). (iv) The real GDP per capita in logarithmic form (hereafter called productivity) is used to identify and investigate shock transmission among countries in real and financial dimensions over time. The weights $s_{i t, j}$ component, corresponding to the sum of rweights $_{i t, j}$ and fweights $_{i t, j}$, and the structures $s_{i t, j}$ one are treated endogenously and used to deal with functional form misspecification and heterogeneity issues in multicountry setups.

The estimation sample covers the period from March 1995 to December 2016. It amounts, without restrictions, to 12, 320 regression parameters. To be more precise, each equation of the time-varying SPBVAR in equation 1 has $k=[10(6+2+$ 6) $] l=140$ coefficients, and there are 88 equations in the system. Since this span of data includes a sufficient number of quarters describing the recent financial crisis and fiscal consolidation, the model, given its structural conformation, is able to capture additional cross-country heterogeneity, interdependence, and commonality due to possible economic-structural linkages.

By diagnostic tests (see Table 2), the factorization in equation 4 is exact. Thus, the specified factors in equation 5 I assume for the empirical analysis can be made clearer (Note 5).

In fact, $\chi_{1 t} \beta_{1 t}$ and $\chi_{2 t} \beta_{2 t}$ are $N \cdot 1$ vectors of observable country-specific indicators for $Y_{t}$, and account for the only real $l_{i t, j}$ and $f_{i n} i_{i t, j}$ components in order to evaluate international transmission of shocks and the evolution of structural spillover effects among countries.

The indicators $\chi_{3 t} \beta_{3 t}$ and $\chi_{4 t} \beta_{4 t}$ are $N \cdot 1$ vectors of observable country-specific effects for $Y_{t}$, and account for two additional components: (1) real rit,j $_{j}$ with rweights $_{i t, j}$ and (2) fin ${ }_{i t, j}$ with fweights $s_{i t, j}$. They are able to assess the role that additional transmission channels play in driving the spread of an unexpected shock in real and financial dimensions and thus investigate unobserved heterogeneity across countries.

The indicators $\chi_{5 t} \beta_{5 t}$ and $\chi_{6 t} \beta_{6 t}$ are $N \cdot 1$ vectors of observable country-specific effects for $Y_{t}$, and account for one additional component: real $_{i t, j}$ with structures $s_{i t, j}$ and fin $_{i t, j}$ with structures $s_{i t, j}$. They are able to investigate how macroeconomicinstitutional implications and potential macroeconomic imbalances affect the transmission of international shocks and the evolution of structural spillovers in real and financial dimensions.

The indicators $\chi_{7 t} \beta_{7 t}$ and $\chi_{8 t} \beta_{8 t}$ are $N \cdot 1$ vectors of observable country-specific effects for $Y_{t}$, and account for two additional components: (1) real rit,j $_{\text {with }}$ rweights $_{i t, j}$ and structures $_{i t, j}$ and (2) fin in $_{i t, j}$ with $f$ weights $_{i t, j}$ and structures $s_{i t, j}$. They are able to investigate how additional transmission channels, macroeconomic-institutional implications, and potential macroeconomic imbalances jointly affect the intensity and the spreading of spillover effects in real and financial dimensions.

The indicator $\chi_{9 t} \beta_{9 t}$ is a $M_{v} \cdot 1$ vector of observable cross-country variable-specific effects for $Y_{t}$, where $M_{v}=\left(M_{v 1}, M_{v 2}, M_{v 3}\right.$, $M_{v 4}, M_{v 5}, M_{v 6}, M_{v 7}, M_{v 8}$ ) denotes the number of variable groups: (i) $M_{v 1}=\operatorname{real}_{i t, j}$; (ii) $M_{v 2}=\operatorname{fin}_{i t, j}$; (iii) $M_{v 3}=\operatorname{real}_{i t, j}$ and rweights $_{i t, j} ;$ (iv) $M_{v 4}=$ fin $_{i t, j}$ and fweights $s_{i t, j} ;(v) M_{v 5}=$ real $_{i t, j}$ and structures $_{i t, j} ;(v i) M_{v 6}=$ fin $_{i t, j}$ and structures $_{i t, j}$; (vii) $M_{v 7}=$ real $_{i t, j}$, rweights $_{i t, j}$, and structures $s_{i t, j}$; and (viii) $M_{v 8}=f_{i n} n_{i t, j}, f w e i g h t s_{i t, j}$, and structures $_{i t, j}$. The factor can be used to investigate possible commonality, heterogeneity, and interdependence in real and financial dimensions among variables, accounting for additional transmission channels, macroeconomic-institutional linkages, and macroeconomic imbalances.

Finally, the indicator $\chi_{10 t} \beta_{10 t}$ is a $M_{c} \cdot 1$ vector of observable common effects for $Y_{t}$, where $M_{c}=\left(M_{c 1}, M_{c 2}, M_{c 3}, M_{c 4}\right)$

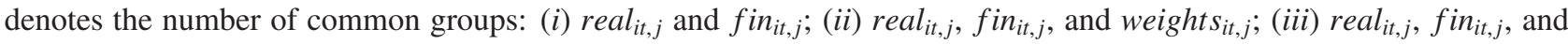


structures $_{i t, j}$; and (iv) real rit,j $_{\text {, }}$ in $_{i t, j}$, weights $s_{i t, j}$, and structures $_{i t, j}$. The factor is able to assess unobserved spillover effects due to different reactions or co-movements among countries and variables for a given a common unexpected shock.

\section{Commonality, Interdependence, and Heterogeneity}

Given the benchmark model in equation 5 and the corresponding selected factors, structural spillover effects given an unexpected shock in real and financial dimensions, accounting for all variables in the system, can be assessed. To be more precise, the dimension and intensification of spillover effects are measured through the Systemic Contribution (SC) index, denoting the amplification contribution of the impulse variable to the response variable and is able to capture sequential features associated with systemic events (Note 6).

In Figure 1, where I consider the first two country-specific indicators $\left(\chi_{1 t}, \chi_{2 t}\right)$, common behaviors matter more in the real dimension, especially among eurozone countries (Note 7). However, there is a consistent degree of heterogeneity among countries in the financial dimension and even more in the real economy. In the financial dimension (Figure $1 b$ ), most countries tend to be net senders of the system and thus unexpected country-specific shocks directly affect a country's own output growth in the financial dimension and then in the real economy because of consistent cross-country interdependencies. The latter is confirmed by a relative homogeneity in the spreading of the structural spillovers.

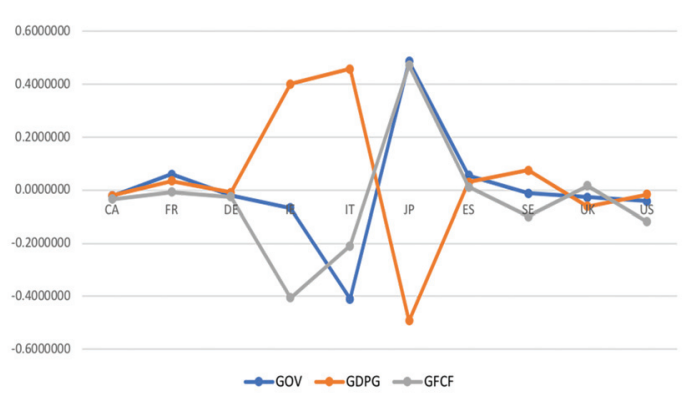

(a) $\chi_{1 t} \hat{\beta}_{1 t}$ Factor - Overall Period

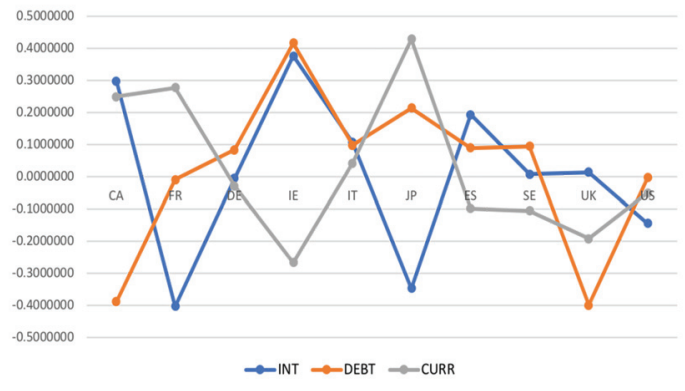

(b) $\chi_{2 t} \hat{\beta}_{2 t}$ Factor - Overall Period

Figure 1. Systemic Contributions of the productivity given a $1 \%$ shock to real and financial dimensions are drawn as standard deviations of the variables in the system and in year-on-year growth rates. They account for $\chi_{1 t} \hat{\beta}_{1 t}(\operatorname{plot} a)$ and $\chi_{2 t} \hat{\beta}_{2 t}$ (plot $b$ ) cross-country indicators, where $\hat{\beta}_{1 t}$ and $\hat{\beta}_{2 t}$ are posterior means

Accounting for weights $_{i t, j}$ and structures $_{i t, j}$ components, important findings and policy perspectives are derived (Figures 2 and 3).

Focusing on the only weights $s_{i t, j}$ component (Figures $2 \mathrm{a}$ and $2 \mathrm{~b}$ ), the intensity of the structural spillovers tend to increase in the real dimension and even more in the financial dimension because of stronger interdependencies. In addition, most countries in the financial dimension follow to be net senders of the system and thus capital income flows would matter more than trade exposures in driving shock transmission. Nevertheless, the degree of commonality tends to decrease among countries in their financial dimension but not in their real economy. Stronger homogeneity is found among countries in the real dimension, except for France and Italy (denoting, with Germany, the continental European area), Japan, and Ireland.

The results of accounting for the structures it,$j$ component (Figures $2 \mathrm{c}$ and $2 \mathrm{~d}$ ) show most divergence across countries and a decreasing of the degree of commonality in the real dimension. The intensity of the structural spillovers is lower than the one observed accounting for the only weight $s_{i t, j}$ component. Their spreading is similar among countries in either the real or the financial dimension, with some common and homogeneous behaviors. In fact, the countries tend to be either net senders or net receivers of the system and thus an unexpected shock affects countries' economy in a similar way because of the presence of stronger economic-institutional linkages. From the above findings, it would confirm a relevant presence of synchronization behind stronger interdependencies across countries when dealing with not directly observed economic issues.

The results are different when accounting for either the weight $_{i t, j}$ or structures $_{i t, j}$ components (Figure 3). To be more precise, the structural spillovers given un unexpected shock are larger in the real economy and even more in the financial dimension. In addition, the intensity and the spreading of spillover effects become obvious to be driven by the structures $_{i t, j}$ and the weight $s_{i t, j}$ components, respectively. It highlights the accuracy of the model estimated in equation 1 when dealing with problems of unobserved heterogeneity.

Two main results follow from the above findings. First, from a modelling perspective, the transmission tends to be more intense among countries in the financial dimension than in the real dimension because of stronger interdependencies. 


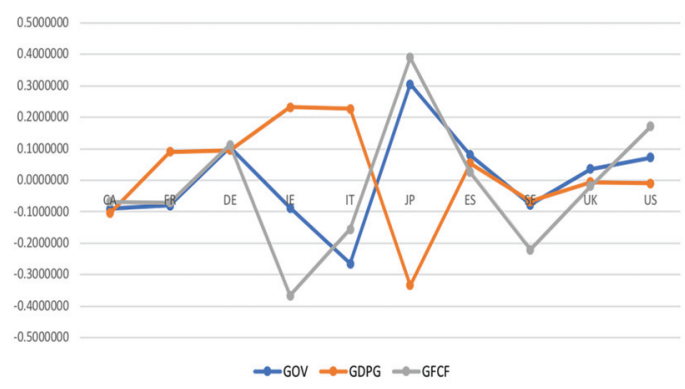

(a) $\chi_{3 t} \hat{\beta}_{3 t}$ Factor - Overall Period

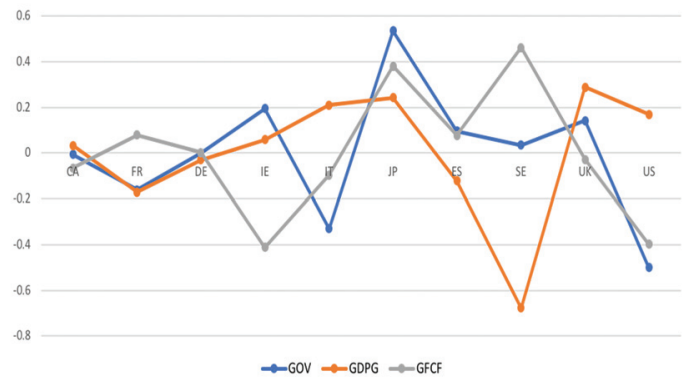

(c) $\chi_{5 t} \hat{\beta}_{5 t}$ Factor - Overall Period

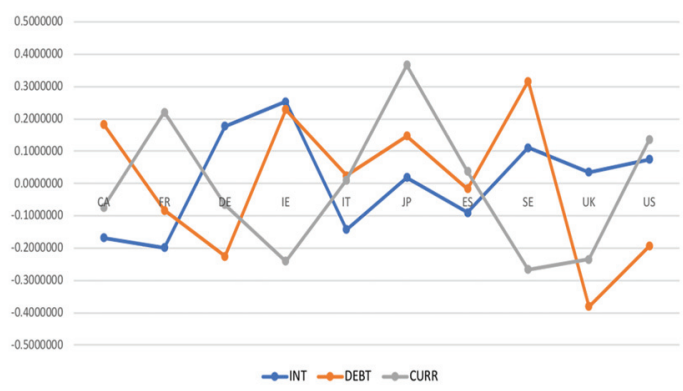

(b) $\chi_{4 t} \hat{\beta}_{4 t}$ Factor - Overall Period

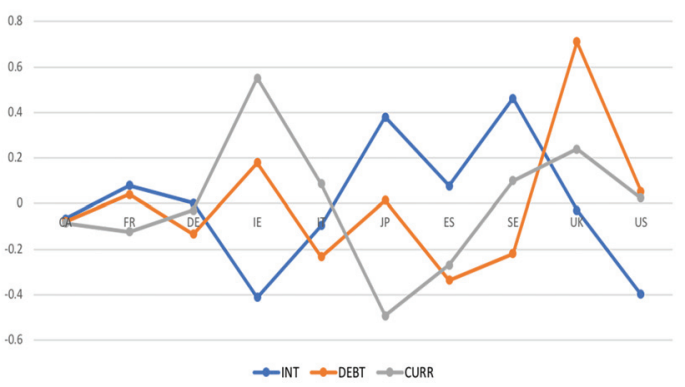

(d) $\chi_{6 t} \hat{\beta}_{6 t}$ Factor - Overall Period

Figure 2. Systemic Contributions of the productivity given a $1 \%$ shock to real and financial dimensions are drawn as standard deviations of the variables in the system and in year-on-year growth rates. They account for $\chi_{3 t} \hat{\beta}_{3 t}$ (plot $a$ ), $\chi_{4 t} \hat{\beta}_{4 t}$ (plot $b$ ), $\chi_{5 t} \hat{\beta}_{5 t}$ (plot $c$ ), and $\chi_{6 t} \hat{\beta}_{6 t}$ (plot $d$ ) cross-country indicators, where $\hat{\beta}_{3 t}, \hat{\beta}_{4 t}, \hat{\beta}_{5 t}$, and $\hat{\beta}_{6 t}$ are posterior means

Moreover, a relevant common component matters more in the real economy because of lower heterogeneities among countries. Second, from a policy perspective, the consolidations tend to occur simultaneously over time behind more coordinated fiscal actions across euro-area countries, but it is not the same for other advanced economies. Cross-country heterogeneity and interdependency in the financial dimension tend to be driven by stringent international institutional constraints and pressures. Thus, without dealing with unobserved heterogeneity, the synchronization seems to be likely decreasing over time due to different countries' reaction given un unexpected shock. Nevertheless, accounting for additional transmission channels and economic issues, I show that the degree of synchronization is relevant across advanced economies and even more across euro-area countries. To be more precise, it is assessed in the real economy where commonality and homogeneity matter more because of relevant international trade exposures.

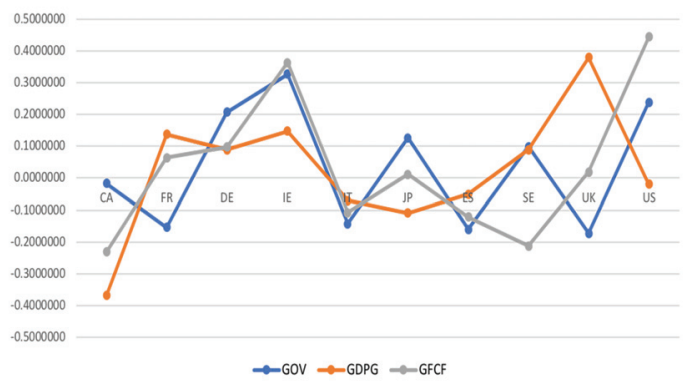

(a) $\chi_{7 t} \hat{\beta}_{7 t}$ Factor - Overall Period

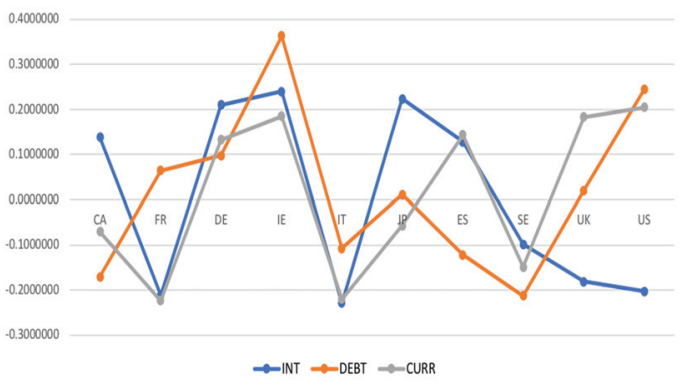

(b) $\chi_{8 t} \hat{\beta}_{8 t}$ Factor - Overall Period

Figure 3. Systemic Contributions of the productivity given a $1 \%$ shock to real and financial dimensions are drawn as standard deviations of the variables in the system and in year-on-year growth rates. They account for $\chi_{7 t} \hat{\beta}_{7 t}$ (plot $a$ ) and $\chi_{8 t} \hat{\beta}_{8 t}$ (plot $b$ ) cross-country indicators, where $\hat{\beta}_{7 t}$ and $\hat{\beta}_{8 t}$ are posterior means

In Figure 4, I consider all the variable-specific factors. Accounting for the only real and financial variables (Figures 4a), on average, most countries in the real and the financial dimensions are inwards (net receivers) and outwards (net senders), respectively. Nevertheless, either the spreading or the intensity of the spillover effects show a relevant heterogeneity component across countries. 


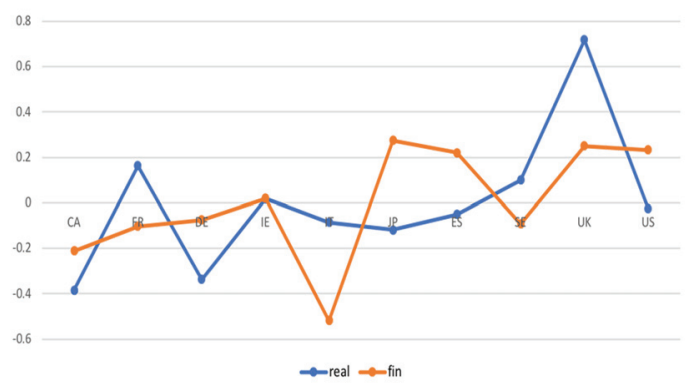

(a) $\chi 9 t, 1 \hat{\beta}_{9 t, 1} \& \chi_{9 t, 2} \hat{\beta}_{9 t, 2}$ Factors - All Period

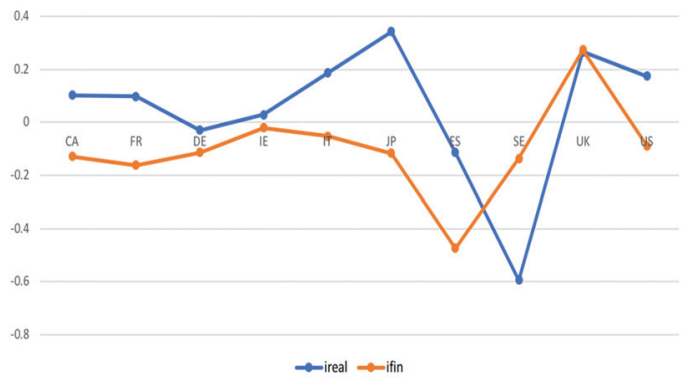

(c) $\chi 9 t, 5 \hat{\beta}_{9 t, 5} \& \chi_{9 t, 6} \hat{\beta}_{9 t, 6}$ Factors - All Period

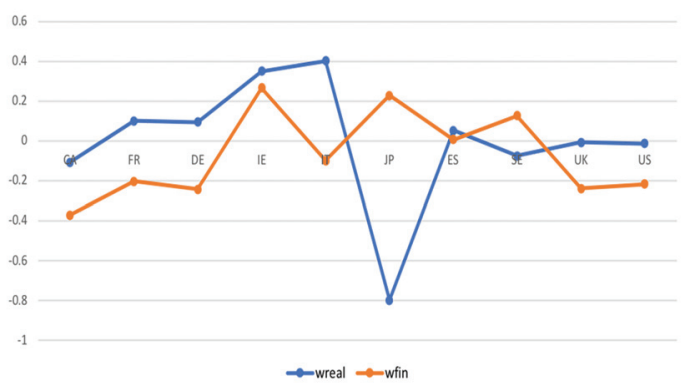

(b) $\chi_{9 t, 3} \hat{\beta}_{9 t, 3} \& \chi_{9 t, 4} \hat{\beta}_{9 t, 4}$ Factors - All Period

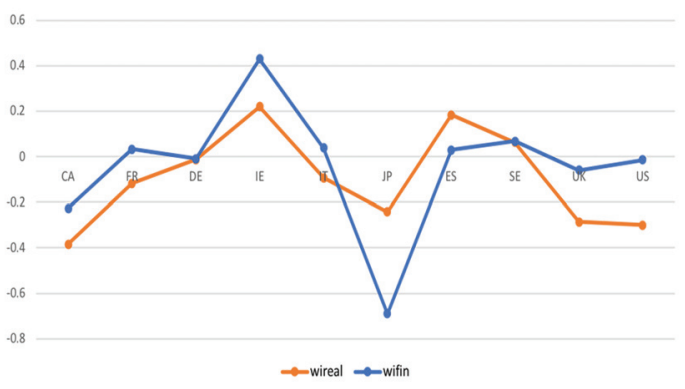

(d) $\chi_{9 t, 7} \hat{\beta}_{9 t, 7} \& \chi_{9 t, 8} \hat{\beta}_{9 t, 8}$ Factors - All Period

Figure 4. Systemic Contributions of the productivity given a $1 \%$ shock to real and financial dimensions are drawn as standard deviations of the variables in the system and in year-on-year growth rates. They account for $\chi_{9 t, 1} \hat{\beta}_{9 t, 1}$ and $\chi_{9 t, 2} \hat{\beta}_{9 t, 2}$ (plot $a$ ), $\chi_{9 t, 3} \hat{\beta}_{9 t, 3}$ and $\chi_{9 t, 4} \hat{\beta}_{9 t, 4}$ (plot $b$ ), $\chi_{9 t, 5} \hat{\beta}_{9 t, 5}$ and $\chi_{9 t, 6} \hat{\beta}_{9 t, 6}$ (plot $c$ ), and $\chi_{9 t, 7} \hat{\beta}_{9 t, 7}$ and $\chi_{9 t, 8} \hat{\beta}_{9 t, 8}$ (plot $d$ ) variable-specific indicators, where $\hat{\beta}_{9 t, M_{v}}$ 's are posterior means

Matching the real $_{i t, j}$ and $f i_{i t, j}$ components with the weights $s_{i t, j}$ one (Figure $4 \mathrm{~b}$ ), a larger degree of homogeneity is found between the real and the financial dimensions. The result confirms the consistent role of the transmission channels in driving the spreading of the structural spillovers given un expected shock. Moreover, the relevant role of capital income flows in absorbing the effects of variable-specific shocks is confirmed not only across the euro-area countries but also across other advanced economies.

Comparing the real $_{i t, j}$ and the $f_{i n} i_{i t, j}$ components with the structures $s_{i t, j}$ one (Figure $4 \mathrm{c}$ ), most countries in the financial dimension seem to be net senders of the system, with a relevant degree of heterogeneity in the spreading of the structural spillovers. Thus, economic-institutional implications have been stronger in the financial dimension over time, mainly among european countries (behind larger fiscal pressures). Moreover, the results prove that the intensity of how shocks spill over is driven by the structures $_{i t, j}$ component.

Finally, matching the real $_{i t, j}$ and fin $_{i t, j}$ components with either the weights $s_{i t, j}$ and the structures $s_{i t, j}$ ones (Figure 4d), two main findings are found. From a modelling perspective, the analysis shows the ability of the model to deal with unobserved heterogeneity. In fact, whether economic issues matter more in reflecting changes in the magnitudes of structural shocks, international trade and financial exposures tend to mainly affect changes in the response of the economies. In addition, the analysis suggests that area-specific common factors play an important role, separating the sample into a North American (US, Canada) and a continental European (France, Germany, Italy) area, with the Ireland and Japan being somewhat separate from these areas (possibly due to different economic-institutional issues). I find that developments in the North American factor have a strong lagged impact on the continental European factor (with larger spillovers), while the reverse is not true. Furthermore, the strength of the cross-area spillovers from America to Europe appears to have become stronger over the sample period, suggesting that international linkages have increased in the process of globalization.

In Figure 5, I consider the last factor, $\beta_{10 t}$. The analysis confirms the importance of accounting for a common group component when studying macroeconomic and financial linkages (see, e.g., Ciccarelli et al. (2018)). Comparing the common factors with and without unobserved heterogeneities (Figure 5a), larger homogeneities are found across the countries' responses absorbed into the $\chi_{10 t, 4} \hat{\beta}_{10 t, 4}$ factor. Moreover, the same factor, jointly evaluated with the weight $s_{i t, j}$ and the structures $_{i t, j}$ components, tends to mitigate the heterogeneity among countries and to reflect co-movements among the real and the financial variables (Figure 5b). Finally, I find confirmation that the spreading and the intensity of the structural spillovers are driven by the weights $s_{i t, j}$ component $\left(\chi_{10 t, 2} \hat{\beta}_{10 t, 2}\right.$ factor) and the structures $s_{i t, j}$ one $\left(\chi_{10 t, 3} \hat{\beta}_{10 t, 3}\right.$ factor), 


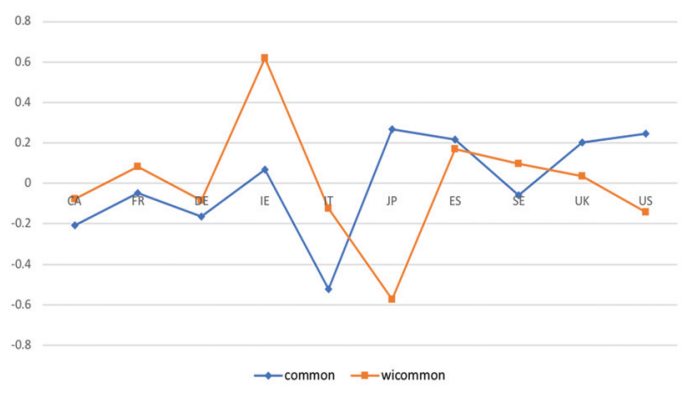

(a) $\chi_{10 t, 1} \hat{\beta}_{10 t, 1} \& \chi_{10 t, 4} \hat{\beta}_{10 t, 4}$ Factors

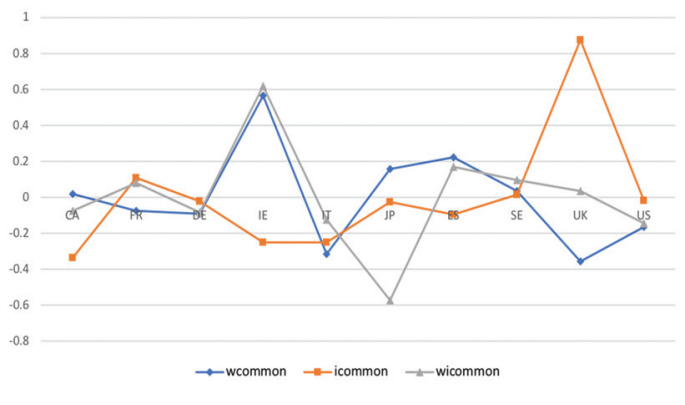

(b) $\chi_{10 t, 2} \hat{\beta}_{10 t, 2}, \chi_{10 t, 3} \hat{\beta}_{10 t, 3} \& \chi_{10 t, 4} \hat{\beta}_{10 t, 4}$ Factors

Figure 5. Systemic Contributions of the productivity given a 1\% shock to real and financial dimensions are drawn as standard deviations of the variables in the system and in year-on-year growth rates, for the full sample. They account for $\chi_{10 t, 1} \hat{\beta}_{10 t, 1}$ (plot $a$ ), $\chi_{10 t, 2} \hat{\beta}_{10 t, 2}$ (plot $b$ ), $\chi_{10 t, 3} \hat{\beta}_{10 t, 3}$ (plot $b$ ), and $\chi_{10 t, 4} \hat{\beta}_{10 t, 4}$ (plots $a$ and $b$ ) common indicators, where $\hat{\beta}_{10 t, M_{c}}$ 's are posterior means

respectively.

\section{Evolution of Spillover Effects During the Great Recession and Fiscal Consolidation}

Previous section provides evidence of significant co-movements in both real economy and financial dimension across developed economies. Moreover, I find that there is a relative homogeneity in the spreading of the structural spillovers among financial sectors and thus unexpected country-specific shocks directly affect a country's own output growth in the financial dimension and then in the real economy because of consistent cross-country interdependencies. When dealing with not directly observed economic issues, I show that the degree of synchronization is relevant across advanced economies and even more across euro-area countries. Accounting for additional transmission channels, I highlight that it mainly assessed in the real economy where commonality and homogeneity matter more because of relevant international trade exposures.

The aim of this section is to gauge the relative weight of these findings in investigating the changes in cyclical comovements among sectors and countries over time and the degree of business cycles synchronization (Section 5.1). Policy implications and suggestions for decision makers are also accounted for (Section 5.2). Thus, I provide to deepen the knowledge about the interactions between real and financial sectors during different phases of business and financial cycles since it is rather limited in the existing literature. This is in large part as most studies have a small set of observations to work with, using a single country (often the United States) or a few advanced countries. The importance of studying the global dimensions of these interactions, however, can no longer be ignored as the dramatic cost of the global financial crisis has shown.

\subsection{Empirical Results}

Generally speaking, financial crises are typically multidimensional events and can be hard to characterize using a single indicator. The existing literature has clarified some of the factors driving crises, but definitively identifying their deeper causes remains a challenge. Many theories have been developed regarding the underlying causes of crises. Although fundamental factors (e.g., macroeconomic imbalances, internal or external shocks) are often observed, many questions remain about the exact causes of crises. Financial crises sometimes appear to be driven by not directly observed factors, including contagion and spillovers among financial markets, limits to arbitrage during times of stress, and other aspects of financial turmoil.

The structural framework of the model allows to provide quantitative estimates of such topics. For example, are they domestic or international in origin? Do they reflect changes in the magnitudes of structural shocks or, rather, changes in the response of the economies to those shocks? How additional transmission channels and economic-institutional issues affect coutries' responses due to an unexpected shock during triggering events?

The empirical analysis suggests important heterogeneity in the shape and the dynamics of international cycles, with countries endogenously reacting to foreign impulses. More precisely, during the recent recession, there are deeper comovements and a larger degree of homogeneity across countries in the real dimension (Figures 6a and 6b) and even more so in the financial dimension compared with successive post-crisis consolidations (Figures $6 \mathrm{c}$ and $6 \mathrm{~d}$ ). These results translate into four main findings. First, interdependencies due to strongly common economic-institutional linkages matter more during triggering events. Second, coordinated fiscal actions do not necessarily yield better outcomes. Third, accounting for unobserved heterogeneity, the persistent common component among countries in the financial dimension 


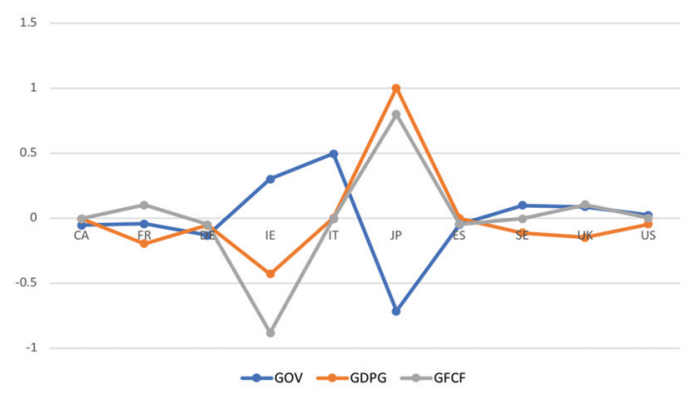

(a) $\chi_{7 t} \hat{\beta}_{7 t}$ Factor - Crisis Period

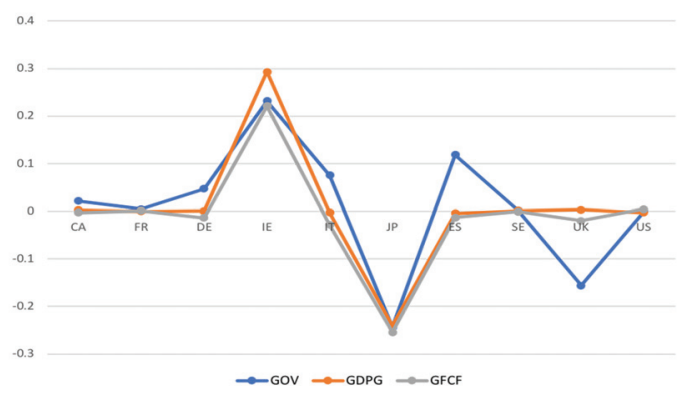

(c) $\chi_{7 t} \hat{\beta}_{7 t}$ Factor - Fiscal Period

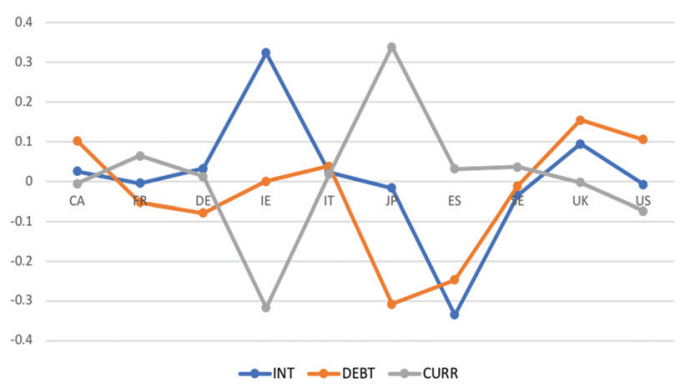

(b) $\chi_{8 t} \hat{\beta}_{8 t}$ Factor - Crisis Period

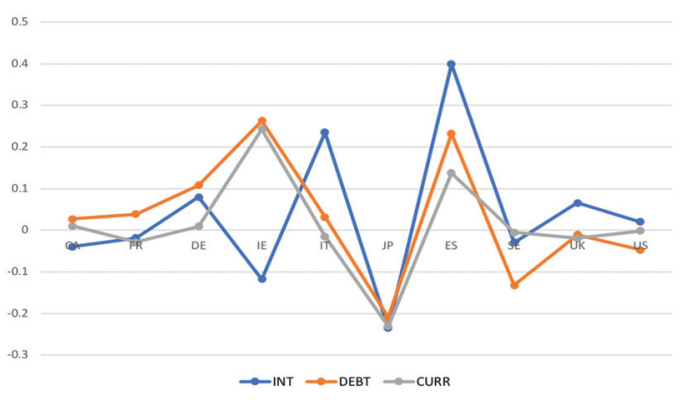

(d) $\chi_{8 t} \hat{\beta}_{8 t}$ Factor - Fiscal Period

Figure 6. Systemic Contributions of the productivity given a $1 \%$ shock to real and financial dimensions are drawn as standard deviations of the variables in the system and in year-on-year growth rates. They account for $\chi_{7 t} \hat{\beta}_{7 t}$ and $\chi_{8 t} \hat{\beta}_{8 t}$ cross-country indicators during crisis period (plots $a$ and $b$ ) and fiscal consolidation (plots $c$ and $d$ ), respectively; where $\hat{\beta}_{7 t}$ and $\hat{\beta}_{8 t}$ are posterior means

and even more in the real economy highlights a relevant synchronization in the last decade. Finally, although recent theoretical studies suggest that a significant improvement in fiscal sustainability has been achieved, the strong and nonlinear reaction of markets, the risk of a cascade of policy errors, and adverse political economy incentives are additional reasons for early and determined fiscal consolidation. They suggest a need for great caution in efforts to fine tune the economy via fiscal structures. Moreover, all euro-area countries need to correct their excessive deficits in accordance with their commitments and reach balanced budgets. The above discussion shows that the chances of successful and sustained consolidation can be increased by strengthening the institutional environment for fiscal policy-making at the national and the international level. Consolidation should generally be based on expenditure reduction, which could provide additional support to long-term growth via reduced distorsions in the economy.

By accounting for the variable-specific indicator (Figure 7), I confirm that trade channels matter less than capital linkages. In fact, most countries tend to be net senders in the financial dimension and net receivers in the real economy. During post-crisis consolidations (Figure 7b), the intensity of the spillover effects sufficiently decreases behind more coordinated fiscal actions. Moreover, by accounting for unobserved heterogeneity, a relevant commonality component holds because of stronger international business cycles synchronization. This suggests that there would be significant benefits from fiscal consolidation without delay and that there is a need for caution against excessive faith in fiscal structures. To achieve the full short-run and long-run benefits, it should be part of an ambitious, comprehensive, and credible reform strategy which will indeed reap a significant improvement in fiscal sustainability.

The common indicator (Figure 8) shows that economic-institutional interdependencies matter more than different transmission channels in driving the intensity and, especially in the last decade, the spread of common unexpected shocks. The findings argue for significant synchronization behind a relevant consolidation in Europe and other advanced economies without delay. Nevertheless, from a policy perspective, different countrys' reactions highlight a need to reduce unsustainable public liabilities with their deleterious effects on long-term growth and confidence. But even in the short term, the benefits of consolidation are likely to outweigh their costs in an environment of strong, non-linear fiscal-financial interlinkages. Consolidation is needed to underpin confidence in fiscal solvency at the country level and prevent adverse international externalities. 


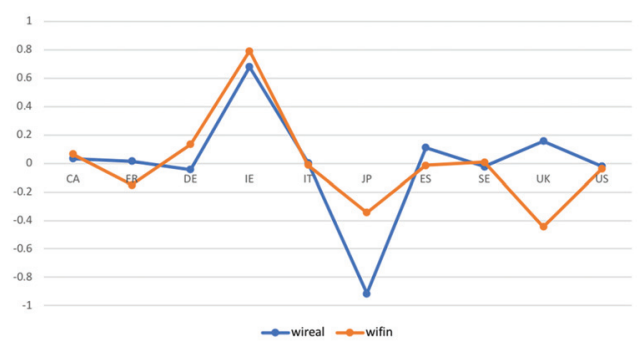

(a) $\chi 9 t, 7 \hat{\beta}_{9 t, 7} \& \chi_{9 t, 8} \hat{\beta}_{9 t, 8}$ Factors - Crisis Period

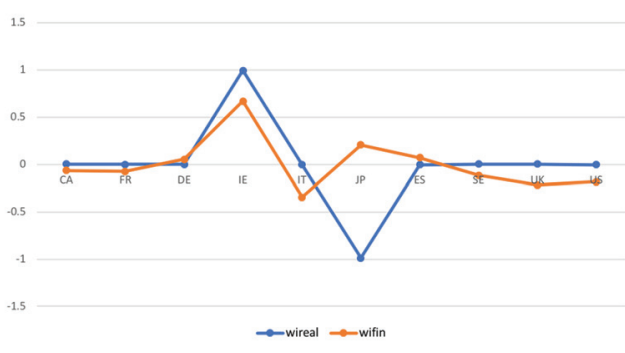

(b) $\chi 9 t, 7 \hat{\beta}_{9 t, 7} \& \chi \chi_{9 t, 8} \hat{\beta}_{9 t, 8}$ Factors - Fiscal Period

Figure 7. Systemic Contributions of the productivity given a $1 \%$ shock to real and financial dimensions are drawn as standard deviations of the variables in the system and in year-on-year growth rates, focusing on the recent financial crisis (plots $a$ ) and post-crisis consolidation period (plot $b$ ). They account for $\chi_{9 t, 7} \hat{\beta}_{9 t, 7}$ and $\chi_{9 t, 8} \hat{\beta}_{9 t, 8}$ variable-specific indicators, where $\hat{\beta}_{9 t, 7}$ and $\hat{\beta}_{9 t, 8}$ are posterior means

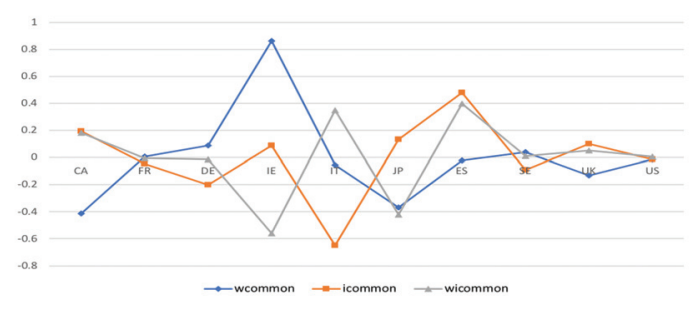

(a) $\chi_{10 t, 2} \hat{\beta}_{10 t, 2}, \chi_{10 t, 3} \hat{\beta}_{10 t, 3} \& \chi_{10 t, 4} \hat{\beta}_{10 t, 4}$ Factors - Crisis Period

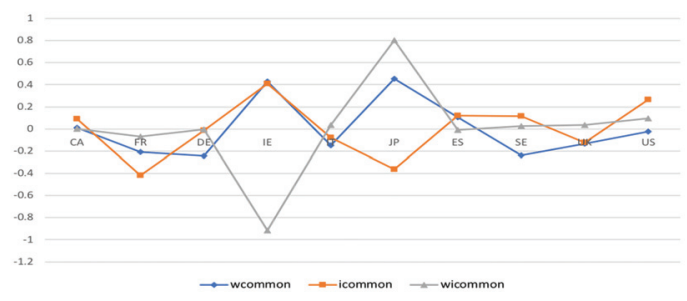

(b) $\chi_{10 t, 2} \hat{\beta}_{10 t, 2}, \chi_{10 t, 3} \hat{\beta}_{10 t, 3} \& \chi_{10 t, 4} \hat{\beta}_{10 t, 4}$ Factors - Fiscal Period

Figure 8. Systemic Contributions of the productivity given a $1 \%$ shock to real and financial dimensions are drawn as standard deviations of the variables in the system and in year-on-year growth rates, focusing on the recent financial crisis (plots $a$ ) and post-crisis consolidation period (plot $b$ ). They account for $\chi_{10 t, 2} \hat{\beta}_{10 t, 2}, \chi_{10 t, 3} \hat{\beta}_{10 t, 3}$, and $\chi_{10 t, 4} \hat{\beta}_{10 t, 4}$ common indicators, where $\hat{\beta}_{10 t, 2}, \hat{\beta}_{10 t, 3}$, and $\hat{\beta}_{10 t, 4}$ are posterior means

\subsection{Purposes, Implications, and Lessons for Policy Making}

The most recent recession caught most economists and policy-makers flat-footed, so the search for predictors of such crises has been a major area of research in recent years. In contrast to past crises, the recent financial crisis was concentrated in advanced economies. This concentration led to significant contagion effects from financial institutions in advanced economies to other countries, through both financial and trade channels. After all, the crisis countries were not only home to the main intermediaries of global capital but also the main importers of goods and services. Differences in institutional and economic settings, including the typically larger size of advanced economies' financial systems, required different policy responses, both macroeconomic and financial (see, e.g., Allen et al. (2009), Bordo et al. (2001), and Crespo-Cuaresma \& Slacik (2009)).

The international activities of financial institutions have not been monitored properly. Before the crisis, the focus of authorities remained primarily on the solvency of individual institutions, rather than on the resilience of the financial system as a whole. This lapse led to an underestimation of the probability and costs of triggering events. Thus, a key lesson from the global financial and economic crisis is that policies for economic growth which have prevailed over the past three decades need a rethink. These trends have led to a relevant widening of cross-country heterogeneities, unprecedented in recent economic history. They also went hand-in-hand with relevant environment degradation. Another lesson from the crisis is that growth has been unsustainable from the point of view of the economy itself. The crisis erupted in the financial system. It revealed that growth relied on weak foundations, too much recourse to debt in some countries, and excessive reliance on exports in others. During the post-crisis consolidation, efforts have been made to put in place stimulatory macroeconomic policies. These measures have been synchronized and thus putting a floor on the economic crisis and kick-starting a recovery. However, as has been common in previous episodes, intervention came late in many countries, significantly raising the real and fiscal costs, and hampering the postcrisis recovery (see, e.g., Bordo \& Haubrich (2017), Das et al. (2012), Fisman (2001), and Furceri \& Zdzienicka (2012)). At the international level, insufficient coordination among regulators and supervisors and the absence of clear procedures for the resolution of global financial institutions hindered efforts to prevent the cross-border transmission of the crisis. Macroeconomic imbalances, measured in terms of house prices, increased before the meltdown, including in Ireland, Spain, United Kingdom, United States, and other markets that subsequently ran into problems. The patterns of house price increases are reminiscent of 
those in earlier major crisis episodes. The overall size of the housing booms and their dynamics are remarkably similar to developments that preceded previous banking crises in advanced economies (see, for istance, Reinhart \& Rogoff (2008)). In addition, the complex interdependencies across countries in their financial system also made responses more difficult than when the financial system consisted primarily of traditional banks (as in many earlier crises). The restructuring of assets became far more complicated because homeowners in many countries have been directly involved. There are no established best practices for dealing with large-scale household defaults and the associated moral hazard problems and distribution issues. Restoring household balance sheets proved to be very complex and prolonged the recovery from the crisis (see, e.g., Rose \& Spiegel (2011), Tomz \& Wright (2007), and Wang \& Wen (2012)).

My empirical approach finds confirmation with these aspects and highlights four main topics from the recent recession. The first three findings find evidence with the Reinhart \& Rogoff (2008)'s studies. First, policymakers have often been better at managing crises than at preventing them, which has been also true in the more recent crisis. Second, relevant heterogeneity across advanced economies has not been clear with respect to the likelihood of experiencing a crisis. Third, both the understanding and magnitudes of various debts are still incomplete. Finally, accounting for economicinstitutional issues, the analysis shows that the lack of deeper restructuring also reflected the limited nature of the available tools. More precisely, many advanced economies did not have the tools in place to resolve complex financial institutions before the crisis. Restructuring often involved budgetary approval for government programs to purchase assets or recapitalize financial institutions, causing delays or inadequate funds. Given the lack of cross-border resolution frameworks, interventions in weak institutions with international spillovers have been often poor. The final result appears to be that much of the cost of the financial crisis has been transferred to the future, in the form of higher public debt and possibly an anemic economic recovery caused by residual uncertainty about continued high private sector indebtedness. Thus, new macroeconomic stabilization policies need to supplement and support necessary financial restructuring.

The empirical results also highlight that four new dimensions played important roles during the more recent recession. First, there has been a widespread use of complex and opaque financial instruments. Second, the interconnections and interdependencies among financial markets, nationally and internationally, with the United States at the core, had increased dramatically in a short time. Third, the degree of heterogeneity of financial institutions accelerated sharply. Fourth, the household sector played a central role (see, for istance, Claessens et al. $(2012,2009)$ and Claessens et al. (2010)).

In light of these results, the analysis suggests that close monitoring of cycles in financial markets should be an integral part of macroeconomic surveillance and policy design. Since both business and financial cycles are often synchronized internationally, it is crucial to consider the global aspects of financial regulation and surveillance policies. My analysis also points to new relevant challenges for future research. To be more precise, the empirical literature about the important roles played by countries' institutional structures and regulatory frameworks in modelling the interactions between business and financial cycles is still limited. Given the importance of these interactions and interdependencies, future researches could examine these topics in a cross-country context using the structural framework I document here as a baseline. In addition, the theoretical literature appears still far from either being able to explain the relevant linkages between the real economy and the financial dimension or from capturing them in models directly useful for policymaking. In particular, models that can quantitatively match the main regularities about the interactions and co-movements between real and financial cycles I assess here are still inadequate, suggesting the importance and the need to account for transmission channels and economic-financial issues when studying multicountry dynamic setups.

\section{Concluding Remarks}

This paper provides new empirical insights in order to give a relevant contribution to the more recent literature on international transmission of shocks and on business cycles synchronization across developed economies, with a particular emphasis in the most recent recession and post-crisis consolidation. A time-varying Structural Panel Bayesian Vector Autoregression model is developed to deal with model misspecification and unobserved heterogeneity problems when studying multicountry dynamic panels. I define a hierarchical prior specification strategy and describe MCMC simulations to calculate posterior distributions of Conditional Generalized Impulse Response Functions and Conditional Forecasts reacting to unexpected perturbations in the innovations of factors in the system. Bayesian methods are used to reduce the dimensionality of the model, structure the time variations, and evaluate issues of endogeneity.

My approach and empirical application focus on a pool of real and financial variables and a set of not directly observed factors for advanced economies. The empirical analysis has two specific objectives. The first is to isolate and to measure how an unexpected shock affects the degree of output growth co-movements amongst advanced economies and thus to assess the relative importance of potential cross-country interconnections and interdependencies among macroeconomicfinancial variables. In addition, the paper investigates the degree of international business cycles synchronization and the changes in cyclical comovements among sectors and countries. The analysis is robust and consistent with the more recent business cycle studies, which recognize the importance of (1) accounting for both group-specific and global factors 
when evaluating cross-country spillovers, (2) separating common shocks from the propagation of country- and variablespecific shocks when studying economic-financial linkages, and (3) accounting for additional transmission channels and economic-institutional issues when using multicountry dynamic data.

From a modelling perspective, the empirical analysis suggests that area-specific common factors play an important role, separating the sample into a North American (US, Canada) and a continental European (France, Germany, Italy) area, with the Ireland and Japan being somewhat separate from these areas. To be more precise, I find that Japanese and US policymakers operated under fundamentally different conditions during their respective financial crises. Japanese policymakers underwent a process of learning, adjustment, and experimentation. This made their response appear, in retrospect, haphazard and ineffective. Comparatively, the US responses came with greater speed, force, and precision. Furthermore, I find that developments in the North American factor have a strong lagged impact on the continental European factor, while the reverse is not true. The strength of the cross-area spillovers from America to Europe appears to have become stronger over the sample period, suggesting that international linkages have increased in the process of globalization. Finally, in contrast to the literature, international business cycles seem to have become more synchronized over time, especially in the last decade, behind an increasing of the spreading and intensity of spillover effects.

From a policy perspective, the empirical application argues that the benefits of consolidation have to be re-assessed given that industrialised countries have entered uncharted areas with unsustainable public debt dynamics and enormous contingent liabilities across sectors and countries coinciding with strong, non-linear and potentially highly adverse fiscalfinancial interlinkages. This suggests that stabilizing public debt-to-GDP at current levels penalizes potential growth, which in turn would make it more difficult to sustain high public debt over the longer run. Therefore, it is imperative to lower public debt over time. However, in the short-run, front-loaded fiscal adjustment is likely to hurt growth prospects, which would delay improvements in fiscal indicators, including deficits, debt, and financing costs. A measured spreed of adjustment, based on a clear medium-term plan, is therefore preferable, if market conditions allow it. The recognition that the fiscal adjustment process will slow down growth, makes it important to ensure that other policies (monetary, financial, and structural policies) are used to support growth when fiscal policy is tightened. The paper goes on to discuss the importance of strong medium-term growth for a successful fiscal consolidation. Reforms in goods, service, and labor markets that improve economic efficiency will boost potential growth, in turn serving as important tools in the fiscal adjustment process.

\section{Acknowledgements}

I gratefully thank the anonymous referee for its useful suggestions.

\section{References}

Allen, F., Babus, A., \& Carletti, E. (2009). Financial crises: Theory and evidence. Annual Review of Financial Economics, 1(1), 97-116. https://doi.org/10.2139/ssrn.1422715

Artis, M. J., \& Zhang, W. (1997). International business cycles and the erm: Is there a european business? International Journal of Finance and Economics, 2, 1-16. https://doi.org/10.1002/(SICI)1099-1158(199701)2:1;1::AIDIJFE31;3.0.CO;2-7

Artis, M. J., \& Zhang, W. (1999). Further evidence on the international business cycles and the erm: Is there a european business? Oxford Economic Papers, 51(1), 120-132. https://doi.org/10.1093/oep/51.1.120

Backus, D., \& Kehoe, P. (1992). International evidence on the historical properties of business cycles. The American Economic Review, 82(4), 864-888.

Baxter, M., \& Stockman, A. (1989). Business cycles and the exchange rate regime: Some international evidence. https://doi.org/10.3386/w2689 Journal of Monetary Economics, 23(3), 377-400.

Beetsma, R., \& Giuliadori, M. (2011). The effects of government purchase shocks: Review and estimates for the eu. Economic Journal, 121(550), F4-F32. https://doi.org/10.1111/j.1468-0297.2010.02413.x

Bordo, M. D., Eichengreen, B., Klingebiel, D., \& Martinez-Peria, M. S. (2001). Is the crisis problem growing more severe? Economic Policy, 16(32), 51-82. https://doi.org/10.1111/1468-0327.00070

Bordo, M. D., \& Haubrich, J. (2017). Deep recessions, fast recoveries, and financial crises: Evidence from the american record. Economic Inquiry, 55(1), 527-541. https://doi.org/10.1111/ecin.12374

Canova, F., \& Ciccarelli, M. (2004). Forecasting and turning point predictions in a bayesian panel var model. Journal of Econometrics, 120(2), 327-359. https://doi.org/10.1016/S0304-4076(03)00216-1

Canova, F., \& Ciccarelli, M. (2009). Estimating multicountry var models. International Economic Review, 50(3), 929-959. https://doi.org/10.1111/j.1468-2354.2009.00554.x

Canova, F., Ciccarelli, M., \& Ortega, E. (2012). Do institutional changes affect business cycles? Journal of Economic Dynamics and Control, 36(10), 1520-1533. https://doi.org/10.1016/j.jedc.2012.03.017 
Canova, F., \& Della, H. (1993). Trade interdependence and international business cycle. Journal of International Economics, 34, 23-47.

Canova, F., \& Marrinan, J. (1998). Sources and propagation of international cycles: Common shocks or transmission? Journal of International Economics, 42, 133-167. https://doi.org/10.1016/S0022-1996(97)00038-X

Cantor, R., \& Mark, N. (1987). International debt and world business fluctuations. International Economic Review, 6(2), 153-165. https://doi.org/10.1016/0261-5606(87)90030-1

Carter, C. K., \& Kohn, R. (1994). On gibbs sampling for state space models. Biometrika, 81(3), 541-553. https://doi.org/10.1093/biomet/81.3.541

Chib, S. (1995). Marginal likelihood from the gibbs output. Journal of the American Statistical Association, 90(432), 1313-1321. https://doi.org/10.2307/2291521

Chib, S. (1996). Calculating posterior distributions and model estimates in markov mixture models. Journal of Econometrics, 75(1), 79-97. https://doi.org/10.1016/0304-4076(95)01770-4

Chib, S., \& Albert, J. H. (1993). Bayes inference via gibbs sampling of autoregressive time series subject to markov mean and variance shifts. Journal of Business and Economic Statistics, 11(1), 1-15. https://doi.org/10.2307/1391303

Chib, S., \& Jeliazkov, I. (2001). Marginal likelihood from the metropolis-hastings output. Journal of the American Statistical Association, 96(453), 270-281. https://doi.org/10.1198/016214501750332848

Ciccarelli, M., Ortega, E., \& Valderrama, M. T. (2018). Commonalities and cross-country spillovers in macroeconomicfinancial linkages. Journal of Macroeconomics, 16(1), 231-275.

Claessens, S., Dell'Ariccia, G., Igan, D., \& Laeven, L. (2010). Cross-country experience and policy implications from the global financial crisis. Economic Policy, 25(62), 267-293.

Claessens, S., Kose, A. M., \& Terrones, M. E. (2009). What happens during recessions, crunches and busts? Economic Policy, 60(60), 653-700. https://doi.org/10.2139/ssrn.1318825

Claessens, S., Kose, A. M., \& Terrones, M. E. (2012). How do business and financial cycles interact? Journal of International Economics, 87(1), 178-190. https://doi.org/10.1016/j.jinteco.2011.11.008

Crespo-Cuaresma, J., \& Slacik, T. (2009). On the determinants of currency crisis: The role of model uncertainty. Journal of Macroeconomics, 31(4), 621-632. https://doi.org/10.2139/ssrn.1087984

Das, U. S., Papaioannou, M. G., \& Trebesch, C. (2012). Sovereign debt restructurings 1950-2010: Literature survey, data, and stylized facts. IMF Working Paper, (12/203).

Dees, S., Di Mauro, F., Pesaran, M., \& Smith, L. (2007). Exploring the international linkages of the euro area: a global var analysis. Journal of Applied Econometrics, 22(1), 1-38. https://doi.org/10.1002/jae.932

Doyle, B. M., \& Faust, J. (2003). The effects of financial crisis on fiscal positions. International Finance Discussion Papers, 786.

Fisman, R. (2001). Estimating the value of political connections. American Economic Review, 91(4), 1095-1102. https://doi.org/10.1257/aer.91.4.1095

Forni, M., Hallin, M., Lippi, M., \& Reichlin, L. (2000). The generalized dynami factor model: Identification and estimation. The Review of Economics and Statistics, 82(4), 540-554. https://doi.org/10.1162/003465300559037

Furceri, D., \& Zdzienicka, A. (2012). How costly are debt crises? Journal of International Money and Finance, 31(4), 726-742. https://doi.org/10.1016/j.jimonfin.2012.01.012

Gregory, A. W., Head, A. C., \& Raynauld, J. (1997). Measuring world business cycles. International Economic Review, 38(3), 677-701. https://doi.org/10.2307/2527287

Inklaar, R., \& De Haan, J. (2001). Is there really a european business cycle? a comment. Oxford Economic Papers, 53(2), 215-220. https://doi.org/10.1093/oep/53.2.215

Kadiyala, R. K., \& Karlsson, S. (1997). Numerical methods for estimation and inference in bayesian var models. Journal of Applied Econometrics, 12(2), 99-132. https://doi.org/10.1002/(SICI)1099-1255(199703)12:2 i99::AIDJAE429;3.0.CO;2-A

Koop, G. (1996). Parameter uncertainty and impulse response analysis. Journal of Econometrics, 72(1-2), 135-149. https://doi.org/10.1016/0304-4076(94)01717-4

Pacifico, A. (2019). Structural panel bayesian var model to deal with model misspecification and unobserved heterogeneity problems. Econometrics, 7(1), 1-24.

Pesaran, H. M., \& Shinb, Y. (1998). Generalized impulse response analysis in linear multivariate models. Economics Letters, 58(1), 17-29. https://doi.org/10.1016/S0165-1765(97)00214-0

Reinhart, C. M., \& Rogoff, K. S. (2008). Is the 2007 u.s. subprime crisis so different? an international historical comparison. American Economic Review, 98(2), 339-344. https://doi.org/10.3386/w13761 
Rose, A. K., \& Spiegel, M. M. (2011). Cross-country causes and consequences of the 2008 crisis: Early warning. European Economic Review, 55(3), 309-324.

Tomz, M., \& Wright, M. L. J. (2007). Do countries default in 'bad times'. Journal of the European Economic Association, 5(2-3), 352-360. https://doi.org/10.2139/ssrn.1026384

Wang, P., \& Wen, Y. (2012). Speculative bubbles and financial crises,. American Economic Journal: Macroeconomics, 4(3), 184-221. https://doi.org/10.1257/mac.4.3.184

\section{Notes}

Note 1. To be more precise, if the elements of $A_{t}(L), B_{t}(L)$, and $C_{t}(L)$ are stacked over $i$, it is possible to obtain matrices that are not block-diagonal for at least some $l$.

Note 2. See, for istance, Pacifico (2019) for an illustration of the conformation of the SPBVAR model and the exact form of the $\beta_{f t}$ 's and the $G_{f}$ 's.

Note 3. The factorization of $\gamma_{t}$ becomes exact as long as $\sigma^{2}$ converges to zero.

Note 4. See, for istance, Pacifico (2019) for a clarification on the hierarchical prior strategy performed in this analysis.

Note 5. See, for istance, Pacifico (2019) for further specifications.

Note 6. See, e.g., Pacifico (2019).

Note 7. They account for France, Germany, Italy, Ireland, and Spain.

Note 8. See, e.g., Chib \& Greenberg (1995).

Note 9. See, for istance, Pacifico (2019) for a clarification of prior assumptions and posterior distributions.

Note 10. Own computations.

Note 11. The conditional projection for output growth is the one that the model would have obtained over the same period conditionally on the actual path of unexpected shock for that period.

Note 12. The unconditional projection is the one that the model would obtain for output growth for that period only on the basis of historical information, and it is consistent with a model-based forecast path for the other variables.

\section{Appendix A}

\section{Data Appendix}

The series are expressed in standard deviations with respect to the same quarter of the previous year $\left(q_{t} / q_{t-1}\right)$ and seasonally and calendar adjusted. All variables are used in year-on-year growth rates and all data points originate from Eurostat and OECD data sources.

Table 1. Descriptive Statistics

\begin{tabular}{ll}
\hline VARIABLES & DESCRIPTION \\
\hline General Government Spending & Financial accounts for general government spending. \\
Gross Fixed Capital Formation & Investments of fixed assets at current prices weighted. \\
GDP Growth Rate & It is calculated as: $\log \left(\frac{G D P_{i t, j}}{G D P_{i t, 1, j}}\right)$. \\
General Government Debt & Non-financial accounts for general government debt (\% GDP). \\
Current Account Balance & Non-financial accounts for general government net (\% GDP). \\
Interest Rate & Long term interest rate. \\
Bilateral Flows of Trade & Exports and imports in goods. \\
Bilateral Flows of Capital & Net financial transactions on the total economy. \\
Net International Investments & Total international investment position. \\
Nominal Labour Cost & It is defined as the ratio of labour costs to labour productivity. \\
General Government Consumption & Total general government expenditure at current prices. \\
Private Sector Consumption & Final consumption expenditure. \\
Change of Unemployment Rate & Growth rate of the unemployment rate (\% GDP). \\
House Price Indices & It is defined as the residential property prices indices. \\
Productivity & It corresponds to logarithm of the real GDP per capita. \\
\hline
\end{tabular}

Note. General government spending and consumption, gross fixed capital formation, bilateral flows of trade and capital, international investments, and private consumption variables are weighted for the GDP. 


\section{Appendix B}

\section{Diagnostic Tests}

Table 2 shows some main diagnostic tests to verify the robustness and consistency of the model. The estimates would be asymptotically consistent given the absence of serial correlations between residuals. According to time-variant factors and the Schwarz approximation, the marginal (conditional) likelihood estimation for the factorization $f$ has been tested. The latter confirms the exact $\gamma_{t}$ 's factorization, as the p-value of the test equals $4.84 e^{-8}$.

Table 2. Diagnostic Tests

\begin{tabular}{|c|c|c|c|c|}
\hline Test & Test & Statistics & Degrees of freedom & p-value \\
\hline$L G B_{\pi}$ & & 10153 & 2430 & 0.00 \\
\hline$P_{\pi}$ & & 741.90 & 540 & 0.304 \\
\hline$M L E_{f}$ & & 58.18 & 12 & $4.84 e^{-8}$ \\
\hline
\end{tabular}

Note. $L G B_{\pi}$ stands for a Multivariate Ljung-Box Test of the series, with lags $\pi=30 ; P_{\pi}$ refers to the Portmanteau (Asymptotic) Test on the residuals, with lags $\pi=30 ; M L E_{f}$ is the Marginal (Conditional) Likelihood Estimation Test obtained through the Schwartz approximation, with $f=8$.

\section{Appendix c}

\section{Posterior Distributions}

Supposing exact factorization and letting $\phi_{0}=\left(\Sigma_{e}^{-1}, h_{f 0}, \beta_{0}\right)$ be the prior densities, the posterior distributions for $\phi=$ $\left(\Sigma_{e}^{-1}, h_{f t},\left\{\beta_{t}\right\}_{t=1}^{T}\right)$ are calculated by combining the prior with the (conditional) likelihood for the initial conditions of the data. Thus, the resulting function is proportional to:

$$
L\left(Y^{T} \mid \phi\right) \propto\left(\Sigma_{e}\right)^{-\frac{T}{2}} \exp \left\{-\frac{1}{2}\left[\Sigma_{t}\left(Y_{t}-\left(\Theta_{t} G\right) \beta_{t}\right)^{\prime}\right] \Sigma_{e}^{-1}\left[\Sigma_{t}\left(Y_{t}-\left(\Theta_{t} G\right) \beta_{t}\right)\right]\right\}
$$

where $Y^{T}=\left(Y_{1}, \ldots, Y_{T}\right)$ denotes the data, $\phi=\left(\Sigma_{e}^{-1}, h_{f t},\left\{\beta_{t}\right\}\right)$ refers to the unknowns whose joint distribution needs to be found, and $\left(\phi \mid Y^{T}\right)=\frac{p(\phi) L\left(Y^{T} \mid \phi\right.}{p\left(Y^{T}\right)} \propto p(\phi) L\left(Y^{T} \mid \phi\right)$ is given by the Bayes rule.

Despite the dramatic parameter reduction obtained with equation 5 , the analytical computation of posterior distributions $\left(\phi \mid Y^{T}\right)$ is unfeasible. Thus, through Monte Carlo techniques, a variant of the Gibbs sampler approach can be used in this framework by making use of the Kalman filter (Note 8), so it only requires knowledge of the conditional posterior distribution of $\phi$. Denoting $\phi_{-k}$ the vector $\phi$ excluding the parameter $\varkappa$, these conditional distributions (Note 9) are:

$$
\begin{aligned}
\beta_{t} \mid Y^{T}, \phi_{-\beta_{t}} \sim N\left(\tilde{\beta}_{t \mid T}, \bar{R}_{t \mid T}\right) & \text { or } & p\left(\beta_{t} \mid Y^{T}, \phi_{-\beta_{t}}\right)=N\left(\tilde{\beta}_{t \mid T}, \bar{R}_{t \mid T}\right) \\
\Sigma_{e} \mid Y^{T}, \phi_{-\Sigma_{e}} \sim i W\left(\hat{z}_{1}, \hat{\beta}_{1}\right) & \text { or } & p\left(\Sigma_{e} \mid Y^{T}, \phi_{-\Sigma_{e}}\right)=i W\left(\hat{z}_{1}, \hat{\beta}_{1}\right) \\
h_{f t} \mid Y^{T}, \phi_{-h_{f t}} \sim I G\left\{\frac{\bar{\omega}_{f}}{2}, \frac{\bar{S}}{2}\right\} & \text { or } & p\left(h_{f t} \mid Y^{T}, \phi_{-h_{f t}}\right)=I G\left\{\frac{\bar{\omega}_{f}}{2}, \frac{\bar{S}}{2}\right\}
\end{aligned}
$$

where

$$
\begin{gathered}
\tilde{\beta}_{t \mid T}=\tilde{R}_{t \mid T}\left[\bar{R}_{t \mid T}^{-1} \bar{\beta}+\sum_{t=1}^{T}\left(\Theta_{t} G\right)^{\prime} \Sigma_{e}^{-1}\left(\Theta_{t} G\right) \hat{\beta}\right] \\
\tilde{R}_{t \mid T}=\left[\bar{R}_{t \mid T}^{-1}+\sum_{t=1}^{T}\left(\Theta_{t} G\right)^{\prime} \Sigma_{e}^{-1}\left(\Theta_{t} G\right)\right]^{-1}
\end{gathered}
$$

The $\hat{\beta}$ is the Generalized Least Squares (GLS) estimator, with $\hat{\beta}=\left[\left(\Theta_{t} G\right)^{\prime} \Sigma_{e}^{-1}\left(\Theta_{t} G\right)\right]^{-1} \cdot\left(\Theta_{t} G\right)^{\prime} \Sigma_{e}^{-1} Y_{t}$. By rearranging terms, equation 11 can be rewritten as

$$
\tilde{\beta}_{t \mid T}=\tilde{R}_{t \mid T}\left[\bar{R}_{t \mid T}^{-1} \bar{\beta}+\sum_{t=1}^{T}\left(\Theta_{t} G\right)^{\prime} \Sigma_{e}^{-1} Y_{t}\right]
$$


where $\tilde{\beta}_{t \mid T}$ and $\tilde{R}_{t \mid T}$ denote the smoothed one-period-ahead forecasts of $\beta_{t}$ and of the variance-covariance matrix of the forecast error, respectively; $\hat{z}_{1}=z_{1}+T, \hat{\beta}_{1}=\beta_{1}+\sum_{t}\left(Y_{t}-\left(\Theta_{t} G\right) \beta_{t}\right), \bar{\omega}_{f}=K+\bar{\omega}_{0}$, and $\bar{S}=S_{0}+\Sigma_{t}\left(\beta_{t}^{f}-\beta_{t-1}^{f}\right)^{\prime}\left(\beta_{t}^{f}-\beta_{t-1}^{f}\right)$, with $\beta_{t}^{f}$ denoting the $f^{\text {th }}$ subvector of $\beta_{t}$ and $f$ referring to the factors described in equation 3 .

In this empirical application, the hyperparameters were all known (Note 10). To be more precise, the values used are $z_{1}=N \cdot\left(M+M_{v}+M_{c}\right), Q_{1}=\hat{Q}_{1}, \bar{\omega}_{0}=10^{M_{v}+M_{c}}, S_{0}=1.0, \bar{\theta}_{0}=\hat{\theta}_{0}$, and $\bar{R}_{0}=I_{f}$. Here, $\hat{Q}_{1}$ is a block diagonal matrix, with $\hat{\theta}_{1}=\operatorname{diag}\left(Q_{11}, \ldots, Q_{1 N}\right) ; Q_{1 i}$ is the estimated covariance matrix for each $i$, and $\hat{\beta_{0}}$ is obtained with the OLS version of equation 5 .

Dynamic analyses were conducted via accurate MCMC simulations and implementations. The total number of draws was $5000+1000=6000$, which corresponds to the sum of the final number of draws to discard and draws to save, respectively. The study checked convergence by recursively calculating the first two moments of the posterior of the parameters using 1000, 2000, 3000, 4000, and 5000 draws and found that convergence is obtained at about 1000 draws. A total of 1000 draws were used to conduct posterior inference at each $t$. The CGIRFs were computed as the difference between conditional (Note 11) and unconditional (Note 12) projection of output growth for each country in the period from $1995 q 1$ to $2016 q 4$. Here, the outcomes absorb the conditional forecasts computed for a time frame of 12 quarters ( 3 years, until 2019q4). The natural conjugate prior refers to two subsamples, $2006 q 2-2009 q 3$ and $2009 q 4-2016 q 4$, in order to highlight the impact of the recent financial crisis and fiscal consolidation, respectively.

\section{Copyrights}

Copyright for this article is retained by the author(s), with first publication rights granted to the journal.

This is an open-access article distributed under the terms and conditions of the Creative Commons Attribution license (http://creativecommons.org/licenses/by/4.0/). 